\title{
Why Sociolinguistics ought not to have a future
}

Gregersen, Frans

Published in:

Sociolinguistica 14

Publication date:

2000

Citation for published version (APA):

Gregersen, F. (2000). Why Sociolinguistics ought not to have a future. In Sociolinguistica 14 (pp. 6). Max Niemeyer Verlag. 


\section{Why sociolinguistics ought not to have a future}

The very notion of sociolinguistics is an absurdity. Language is a social phenomenon and so there could not be a linguistics which was not social. This is a paraphrase of the gospel according to the prophet William Labov. But, oddly enough, sociolinguistics is there and furthermore it is still not equivalent to linguistics, pure and simple. The lines below attempt to explain why this is still so and to sketch a programme for the integration of the socio and the linguistics so that the linguistics of the next century becomes much more social and the sociolinguistics accordingly much more linguistic.

\section{Historical background}

(A hidden presupposition behind this long preface to a short story is that the American scene is at all relevant for the understanding of the present state of European sociolinguistics. In choosing to unveil the presupposition here, I state it as my firm belief that a specific European empiricial sociolinguistics has never been in existence. Basil Bernstein's early work on the code theory and the promises it held for a joint venture between a Hallidayan and Hasanian functional linguistics never really turned into a separate European branch of sociolinguistics. In a sense all of what I am saying here could be construed to mean that if this had been the case it could have saved us all a lot of trouble.)

The split between sociolinguistics and linguistics cannot be understood if one does not submit the linguistic scene of structuralism to an historical analysis. Sciences diversify according to their empirical work. Empirical work in the USA may be concerned with the native American Indian languages or the languages of Europe spoken in the States. The first became the province of linguistics while the second job was handed over to American dialectology. Thus the linguistic scene in the USA became much like that of the European nation states where there was little interest in the study of linguistic performance in the cities where most of the population lived and where new norms were created and put to the test. One difference however is that the American cities were more openly multilingual than the European cities of the first half of the 20th century. The cities were the melting pots for the American 
society and thus a good number of the inhabitants did not speak English as their first or even their most important language. Since linguistics since the beginning of romanticism has always done duty as a national science tied to the nation states for the world, this was an obvious reason for overlooking the city dwellers. They did not yet make up the nation. This on the other hand is part of the explanation of why the second part of the century witnessed both a linguistics and a dialectology closely occupied with English.

It does not however explain why the transformational paradigm became so focused on psychology instead of sociology. The reasons for this particular state of affairs are buried in the development of Chomskyan generative grammar or, as one might put it, how American empirical structuralism (notably the theory and practice of Z. S. Harris) was turned upside down. Instead of deriving all categories from a painstaking analysis of the empirical data, i.e. practising inductive reasoning by means of substitution tests and other heuristic means, linguistic theory now became devoted to a deductive heuristics and consequently introspection substituted observation and field work.

Still, why focus on the individual instead of taking the point of departure that language was and is a social phenomenon. I think the reasons here are more internal and have to do with the relatively late development of the science of sociology and the central role of (behaviouristic psychology) in American structuralism. It must be remembered that American structuralism was just as little concerned with society in other than ethnographic terms as the transformationalists (the glorious exception is of course Sapir). So the battle ground of linguistics had been staked out long before Chomsky entered the scene. Just as important here is to see that this was never the case for those structuralists, viz. all the European schools, who had read their Saussure and by langue understood language as a social fact. The crucial difference between langue and competence is of course that the first one belongs to the province of sociology or social psychology while the second one is inescapably and solely psychological.

Already we have a glimpse of why the socio- never really entered the front door. When it was eventually born, sociolinguistics was cast as the internal opposition as it were to the structuralist focus on competence. Hymes thought that one could broaden the concept itself and thus get society back in (cf. 'communicative competence') but he had no ideas to sustain empirical work. On the other hand, Labov presented the academic world with a full fledged mature science in establishing the paradigm empirically with his majestic 1966 volume on New York as a speech community. Here we have empirical work unsurpassed by any one ever since but there were some blind spots. The first one has to do with style and the regulating factors behind style shifts, the second one and the one I will concentrate on here was that the definition of the sociolinguistic variable fitted phonetics but not other levels of language. This 
threatened to make sociolinguistics into a sociophonetics leaving variation at the other levels aside.

\section{Coming from Labov}

Sociolinguistics has grown strong by concentrating on the level of language which does not carry cognitive meaning. Thus, the basic tenet of the method of variable analysis was that the variables must be semantically equivalent. This, obviously, is feasible or even advantageous for the phonetic level of language but just as obviously impossible to demand from syntactical or higher order variables. The question now is whether we can define a new level of constancy for these variables which must be seen as the logical next step if sociolinguistics is to develop into a social linguistics. I propose that we can define constants at all the different levels we are able to distinguish in our linguistic theory. Thus we may define constants at the top most level, e.g. sequences of counseling, and take a look at how these sequences may be variably realized by speaker defined by the traditional speaker variables.

(There is another - very interesting - discussion as to what speaker variables will be relevant in the European societies in this century, this issue cannot be broached here.) In this way we get a new and potentially very fruitful line of empirical research relating linguistic means of expressing certain meanings in closely circumscribed contexts in short a new social linguistics which is not a sociolinguistics because all linguistics will be social.

\section{The integration of macro- and microsociolinguistics}

What is needed is the integration of sociology and linguistics. So what is sociology about. It is about power and power structures. The sociolinguistics of Basil Bernstein was an attempt to answer a sociological question (viz. how are social structures transmitted and how do they change?) and the particular response that BB gave was to place language socialization as the key. Socialization is a vast domain and hardly any sociolinguistic research was carried out before Ruqayia Hasan reopened the Bemsteinian issues with her Sidney project (Hasan 1989 and 1996). The reasons for this are instructive. Socialization is interaction and the study of interaction has a tendency of becoming either universalistic (and thus explicitly anti variationist) or historical which again means anthropological and not sociological in its tenets. The study of interaction has to be comparative or otherwise heavily informed by a study of the relevant speaker variables to be sociologically interesting. A new volume on Kid's talk, Hoyle and Adger 1998, is subtitled 'Strategic Language Use in Later 
Childhood' (thus using a term from social psychology or psychology) but is part of a series of Studies in Sociolinguistics. The crucial question still remains to relate interactional studies of language socialization to macrosociolinguistic studies of societies.

Within the confines of a discipline like macrosociolinguistics or the sociology of language it would be perfectly appropriate to ask: What factors determine the choice of language at the societal level and how do the choices made here influence the choices at other levels, e. g. the individual level? One obvious factor is the choice of English as the language of international communication. If politicians believe that a population has to be bilingual with the native language as the first one and English as the second language in order to participate fully in the international industrial development or in the global trade development then the politicians will decide that English has to be furthered within the school system. If this happens it will enhance the prestige of English further and will most certainly lead to more courses taught in English and more demands for better English performance in tests for executive jobs. This may in its turn lead to the influence of the English language at all levels of the native language. From a Danish viewpoint this is a very real fantasy since influential politicians take the perspectives of the IT revolution to mean that English is a sine qua non. The interesting thing is that while the Danish minister of culture is grappling with the formulation of a politics of language which is supposedly to protect Danish from becoming immersed by the English tidewave, a former minister of the environment proposes the exact opposite (or measures which will lead to the exact opposite) - and they belong to the same political party. This shows that the battle between ideology and commerce/economy has linguistic consequences.

The integration of the sociology of language with language variation may also be sought in other more distant corners. It is obvious from many reports that there are differences between the sexes in their use of linguistic variants. It is equally obvious that there are differences between the sexes in their occupational structure. Now, if the occupational structure could be related to the choice of language, or the choices of linguistic variants, we might be able to explain linguistic performance by appealing to the rationality of a differentiation between the sexes in one area leading to the differentiation in another area. Take for instance the trivial fact that women very often have the role of talking to all kinds of customers, in shops or in the public sector. This would lead us to predict that women would be more prone to develop stylistic repertoires with considerably more variation than their male class mates who would be - at least in the trivial sense of belonging at the shop floor - bound to manifest less variation. This may be formulated using the network model of the Milroyal family but I would prefer to bypass this and see it as the rational choice for the role or the function performed. Rational choice models have their own problems but we are far from close to them since we have not yet exploited the models at all. 
Finally, the integration of macro-viewpoints and micro-studies is necessitated by the very fact of multilingualism in Europe. Since all major European cities will become or have already become multilingual sites, the conversational use of more than one language structure has become more and more evident. This calls for an abolishment of the national language paradigm at the level of variables. We can no longer rely solely on the structural analysis of the national languages to furnish us with the constants, we will have to elaborate models for linguistic repertoires which take their multilingual character as the point of departure. The whole model of European linguistic work has to be changed. No longer can e.g. a dictionary or a grammar be empirically adequate for the present century if it brings only material from one 'language'.

\section{The integration of psychology and psycholinguistics into sociolinguistics}

The study of discourse most often positions the interactants as merely role players. But the real problem of discourse analysis of the linguistic performance within institutions is that of precisely sticking to the fundamental fact of sociology: Differences between the role players make the effect of discourse on the role takers different. It is of paramount importance to the effort to grasp the differential effect of the same discourse directed to a class of individuals who have varying backgrounds. In other words, the integration of sociolinguistics and discourse analysis involves the specification of e. g. the pupils in terms of the traditional (or some other theoretically based) speaker variables.

This is obvious in the discourse analysis of e. g. job interviews where no one would deny that there is an important difference between the job seekers in their relations with the interviewers according to their background as specified in speaker variables (Scheuer 1997). This is because the interaction is a one to one or many to one interaction. But the point is just as important if not more important to make in relation to institutions which feature one to many interaction such as schools.

The problem raised by much qualitative research seems on the face of it to be the problem of representativity but it is really more fundamental than that. Take for instance the case of research into classroom practice. At most we are able to document the interaction in say forty lessons (imagine what it takes to transcribe 40 lessons!) out of a total of...? The problem here is not really representativity, though this is a related issue, but that of scale. What we are able to document is the structure of classroom discourse, what we are not able to document is the effect it has on the life history of the individuals partaking in it. The individuals are temporary participants in the classroom. Some of them are just passing by, but most of them have been part of the same classroom for years and years and years ... Only longitudinal research 
might come close to a documentation of what minimal changes have happened for the individuals throughout this (at least) nine year period which we in Europe call 'school'. And the time scale of the documentation would precisely put it outside the realm of linguistics since the masses of text that would make up the data base would eo ipso preclude a linguistic analysis.

The only way for us to judge the effect of classroom discourse on the individual is to integrate knowledge from the systematic study of classroom structure with the study of how different individuals react now and through the reconstruction of life histories (i. e. through going back with them into their life histories as seen from today's vantage point) in and out of school. Obviously, this makes it necessary for the sociolinguist who wants to document the effect of classroom discourse for the various individuals who make up the class, to adopt a theory of psychology (or rather a specific psychological theory) most importantly a theory which is dynamic.

\section{The curious case of conversation}

Conversation analysis has taken over much of the scene within the field of pragmatics, i. e. the field of study where linguistic practices are seen as creating a situation. The situations most often studied by CA researchers stem from ordinary conversations by which we almost always mean discussion or talk from the intimate sphere in the terminology of the theory of 'Öffentlichkeit' by Habermas. But consider how we change the speech acts when we transport them from the familiar sphere of intimacy into the other spheres.

There is a fundamental speech act of evaluation. The characteristics of this speech act are that the speaker makes a judgment according to a norm which is more often than not only implied. In the intimate sphere we will find conversations such as dinner conversations or friendly talk among acquaintances where evaluative remarks will most often be heard as 'compliments' and/or as 'opinions'. That dress is very becoming or Tony Blair is an impostor. The appropriate reaction to a compliment is a thanks accompanied by a minimization and hopefully an offer of a recompliment: Thank you, you really think so, Well I suppose it is not totally unbecoming, by the way I like your hair. An opinion is an invitation to agree or disagree: Yes isn't he, awful the way he treats the poor. Or: I do not quite think so, Peter. Now evaluative statements are essential to e. g. classroom discourse but they are not heard as compliments, nor as opinions in the sense that one can agree or disagree with them but as recognitions or dismissals: Right! The only precondition is that they are uttered by the teacher. There are other contexts where the ordinary rules stated for normal conversation do not apply at all and these are not defined as pedagogical situations - at least not in the strict sense of the word. The case I have in mind, is the situation known in modern 
Danish enterprises as 'medarbejdersamtaler' where a section leader will meet with his employees in order to evaluate the progress made during the year. This interaction is governed by strict rules as to who is to take the initiative and what kinds of speech acts will be produced when. One section of the interview involves mutual evaluation and here evaluative remarks are not heard as compliments but as regulating speech acts, i.e. regulating future behaviour: 'do more of that!' and 'do less of that!'.

I hope to have shown the obvious, viz. that the societal context has to be delineated before we can make any interesting statements about the specific form of the interaction. There is no such thing as ordinary conversation.

\section{Coming from above}

The basic fact is the division of labour. This leads to the establishment of what might conveniently be called spheres of language. These spheres are both specialized fields with special vocabulary and specific speech acts and at the same time more or less institutionalized societal praxis forms. Within these spheres the various activity types may be located which are partly defined as specific linguistic practices and partly as specific societal transactions. Within these again - note that we are here creating a Chinese box within boxes - the speech events take place that we are apt to see when we get typical transcriptions of interactions from the work place, the doctor patient communication or any (other) customer salesman interaction.

It is possible to find common characteristics for a number of activity types across spheres. Thus the doctor patient relationship typically evolves along the same lines as a number of other counseling activities. First there is a section where the advice seeker presents his or her problem. In this sequence, the floor is the advice seeker's whenever he or she wants it. The next sequence is characterized by the advice giver's active search for additional information and by his or her more or less open formulation of hypotheses to be tested as to what the central problem might be. The initiative in this section is the counselor's. Note that the section has no sense if the advice seeker is already aware of what the central problem is and has stated it. This is a characteristic difference between information seeking and advice seeking or counseling.

The final section consists in the giving of advice equivalent to the presentation of the diagnosis and the cure. The various types of linguistic and societal activity we classify as counseling thus share a logic leading to more or less the same sequencing of the interaction. The interesting question is how to relate this type of context to the linguistic means of getting the slots filled. We must at the outset distinguish between those linguistic means that are necessary to manage the interaction as such. Those are the means which CA has brought to our attention. On the other hand, they are just the machinery for getting the real thing going. And the real thing is what makes every 
interaction specific, the meanings expressed by the interacting parties. Since the parties meet always at a certain point in time having their life histories within them as their necessary baggage, every interaction will to a certain extent be particular, a truly historical and in the usual sense unique event. If we do not want to reduce the human sciences to history we must, however, be able to demonstrate that there is a structure and regularity to the way linguistic structures are used to convey certain meanings in the societal contexts just delineated. The interesting question is whether the relationships between the linguistic structures and the meanings which are thinkable/possible/relevant/communicable in a specific context are statistical or systematic, given the relevant definition of context. And the final question is what models we may come up with for the interaction of speaker variables and linguistic variants at all the relevant linguistic levels - still given that we have a relevant definition of the institutional context. These are the central questions for this decade. As you can see, I'm an optimist.

\section{Literature}

Hasan, Ruqaiya 1989: Semantic Variation and Sociolinguistics, Australian Journal of Linguistics 9, 221-275.

Hasan, Ruqaiya 1996: Ways of Saying. Ways of Meaning. Open Linguistics Series. London: Cassell.

Hoyle, Susan M and Carolyn Temple Adger (eds.) 1998: Kids Talk. Strategic Language Use in Later Childhood. Oxford Studies in Sociolinguistics, Oxford: Oxford University Press.

Scheuer, Jann 1997: Den umulige samtale. København: Akademisk.

Kilde: Ammon, U., Mattheier, K. and Nelde, P. (eds.) Sociolinguistica 14, Tübongen: Niemayer 2000, 26-32. 